\title{
Continuous monitoring of water loading of trees and canopy rainfall interception using the strain gauge method
}

\author{
Y.S. Huang ${ }^{\mathrm{a}, 1}$, S.S. Chen ${ }^{\mathrm{a}, 1}$, T.P. Lin ${ }^{\mathrm{b}, *}$ \\ ${ }^{a}$ Division of Forest Utilization, Taiwan Forestry Research Institute, 53 Nan-hai Road, Taipei 100, Taiwan, ROC \\ ${ }^{\mathrm{b}}$ Institute of Plant Biology, Life Science Building, National Taiwan University, Roosevelt Road, Section 4, Taipei 100, Taiwan, ROC
}

Received 16 October 2003; revised 20 August 2004; accepted 27 August 2004

\begin{abstract}
A non-destructive continuous monitoring technology was developed for documenting diurnal changes in branch weight using resistance strain gauges. The capacity of rainfall interception by the canopy can be directly measured by attaching strain gauges to the branch. The amount of water loaded in tree reaches a maximum in the early morning, and a minimum in the afternoon. Thus, the branch is the heaviest in the early morning, and the lightest in the afternoon. Differences between the weight in the morning and in the afternoon can represent as the daily change in water loading of the branch. The branch can be considered as an elastic cantilever in response to the changes in weight of water carried by the branchlets and leaves, and the changes in strain are caused by the change in the bending stress of branch. Thus, the branch increases its weight when rainfall interception occurs, that also changes the stress of branch. The technique reported in this paper will provide an effective approach to investigating biological biometrics.
\end{abstract}

(C) 2004 Elsevier B.V. All rights reserved.

Keywords: Araucaria cunninghamia Sweet; Neolitsea parvigemma (Hay.) Kanehira and Sasaki; Rainfall interception; Strain gauge; Moment; Canopy

\section{Introduction}

Electric-resistance strain gauges are frequently used as sensors in transducers designed to measure such quantities as strain, load, torque, pressure and acceleration. For the commercial development and extensive utilization by industrial and academic

\footnotetext{
*Corresponding author. Tel.: +886 2 23630231x3832; fax: +886223689564 .

E-mail address: tpl@ntu.edu.tw (T.P. Lin).

${ }^{1}$ Fax: +886223035738.
}

laboratories throughout the world, the strain gauge monitored with a Wheatstone bridge has become a highly perfected measuring system. Precise results for surface strains can be obtained quickly using relatively simple methods and inexpensive gauges and instrumentation system (Jame and William, 1978). Strain gauges were successfully used in the measurement of growth stress in tree trunk and also the diurnal change in circumferential strain of stem (Kikata, 1972; Yoshida et al., 1999). In this article, we present the first application of strain gauge method to monitor directly the rainfall interception. 
It is known that the canopy can intercept rainfall and prevent soil erosion, because intercepted rainfall gradually falls to the ground and evaporates. Traditionally, the amount of precipitation intercepted by the canopy has been determined indirectly from the difference between the measured precipitation and the amount reaching the ground as throughfall and stemflow (Dolman, 1987; Dunin et al., 1988; Johnson, 1990). However, a portion of the rainfall never reaches the ground because the water intercepted by leaves, branches and stems evaporates by a process called 'wet-canopy-evaporation' or 'interceptionloss'. A further portion is temporarily stored by the canopy, and then drips from canopy surfaces as 'leafdrip', or is channeled down tree stems as 'stemflow'. Within rainfall partitioning, stemflow is usually considered a minor forest process, typically being $3-10 \%$ of the total annual budget (Davie and Durocher, 1997). In addition, sophisticated models have been developed to analyze the rainfall interception in forest (Rutter et al., 1971, 1975; Rutter and Morton, 1977; Gash and Morton, 1978; Davie and Durocher, 1997; Xiao et al., 2000; Amatya and Skaggs, 2001; Alavi et al., 2001; Calder, 2001; Chappell et al., 2001). A pioneering paper in the direct measurement of water storage on a forest canopy was that of Hancock and Crowther (1979), who used a displacement transducer to monitor the cantilever deflection changes of a water-laden branch. Although, the use of wire strain gauges was abandoned due to high cost and inconvenience, this situation has changed completely in recent years due to the development of a new generation of strain gauges. As a result, the capacity of canopy to intercept rainfall can be monitored directly and continuously by the strain gauge technique. Basically the method is quite simple in operation. Branch was considered as an elastic cantilever, which bends in response to its weight change owing to rain interception. Strain gauges were bonded on the upper side and the lower side of branch at position near the base. Bending strain which is proportional to the weight change of the branch was then monitored.

In this paper, we describe an experiment evaluating the strain gauge method for estimating interception by branches, and compare our results with that of the displacement transducer method described above.

\section{Materials}

One tree each of Araucaria cunninghamia Sweet (25-year old) (Araucariaceae) and Neolitsea parvigemma (Hay.) Kanehira and Sasaki (10-year old) (Lauraceae), growing at the Taiwan Forestry Research Institute in Taipei $\left(121^{\circ} 30^{\prime} \mathrm{E}, 25^{\circ} 02^{\prime} \mathrm{N}, 6 \mathrm{~m}\right.$ altitude) was used for various measurements. The A. cunninghamia was $10 \mathrm{~m}$ tall, $27.5 \mathrm{~cm}$ in diameter at breast height; with 24 branches arranged in several rings. Since branches were horizontal and uniform in shape, only one lower branch was needed for measurement. This branch had an approximate mass of $12 \mathrm{~kg}$, length of $3.5 \mathrm{~m}$, and $5 \mathrm{~cm}$ in diameter near the trunk. The $N$. parvigemma is $7 \mathrm{~m}$ tall, and $9.5 \mathrm{~cm}$ in diameter at base. Because the angles between branches and branching morphology were different, four branches were used for measurement, with branches $\mathrm{A}, \mathrm{B}, \mathrm{C}$ and $\mathrm{D}$ having diameters of 1.8 , $2.3,1.8$ and $2.4 \mathrm{~cm}$, respectively. The measurements were done between July and September 1999 with air temperature between 25 and $35^{\circ} \mathrm{C}$.

\section{Methodology}

Strain gauge method in this article is to use a simple sensitive devise to attach to the inner bark to measure the strain (unit elongation or contraction). Strain monitored is proportional to the loaded weight received by branches, for example from precipitation. After appropriate calibration changes in the strain can be converted to changes in weight. The principle of measurement here considers a branch as an elastic bending cantilever in response to weight changes due to the addition or loss of water. Within the elastic limit, maximal bending stress is generated on the upper and lower side of cantilever when weight is applied on it. The stress should be in proportion to the loading weight, as is the strain. Thus, the weight change can be calculated from the measurement of strain. The water content (weight) of a branch varies between day and night, and between rainy and sunny days. Thus, it is theoretically possible to infer the weight changes by measuring the strain changes. The length of the strain gauge used in this experiment was $5 \mathrm{~mm}$, and the electrical resistance was $120 \Omega$ (Kyowa KFW Type, Japan). The bridge output was delivered 
through a strain amplifier (Kyowa DPM 603A Model) to a data logger (Kyowa UCAM 10B Model and Yokogawa HP1300 Model, Japan), and was recorded, as in the figures presented in this report.

\subsection{Determine the weight center of branch}

Before the experiment, it was necessary to obtain a calibration between weight and strain. As shown in Fig. 1, we hypothesize that the weight center of a branch carrying water is same as the mass center of the branch. We determine the center of branch by visual judgment, representing by $C$.

\subsection{Instrumentation}

To measure the weight changes of branches, strips of the outer bark on the upper and lower sides not far away from the main trunk were removed, and strain gauges were attached to the inner bark in an axial direction using cyanoacrylate resin (Fig. 1). The twogauge method of bridge circuit was used to eliminate the effect of temperature variation on bridge output. Connecting the output of the bridge to a dynamic strain amplifier and data logger, the strain gauge is ready for measurement.

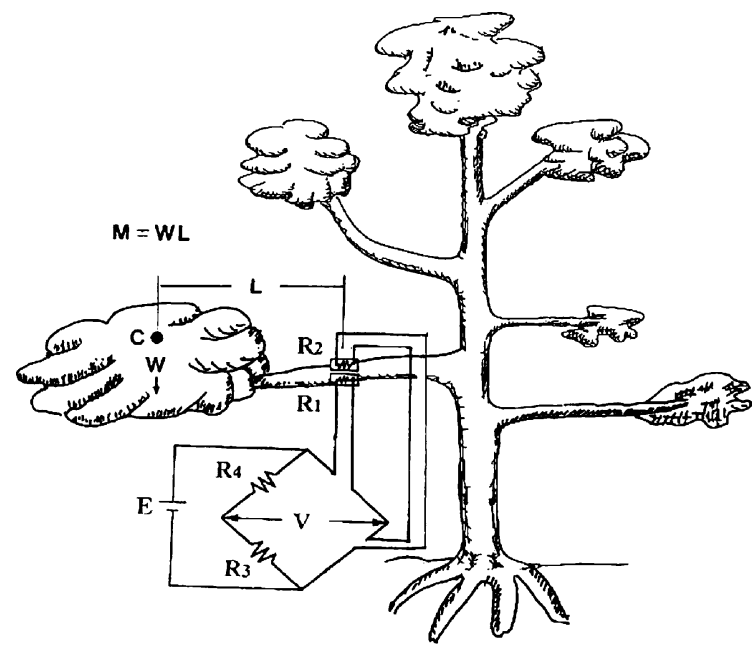

Fig. 1. Diagram showing the measurement of weight change of branch using electrical strain gauge. $M$, moment; $W$, weight; $L$, length from strain gauge to the center of branch; $C$, center of gravity of branch; $R_{1}, R_{2}, R_{3}, R_{4}$, electrical resistance; $E$, source voltage; $V$, output voltage.

\subsection{Calibration}

Various known weights $(W)$ were hung on the center of branch and the strain $(\varepsilon)$ output of bridge was recorded. A strain $(\varepsilon)$ is defined as the change in length of a line segment $(\Delta \iota)$ between two points divided by the original length of the line segment $(\iota)$. The unit $\mu \varepsilon=10^{-6}$ is often used in experiment. A proportional relationship exists between the strain output and bending moment. Moment is expressed as WL ( $L$, the horizontal distance between the weight center and strain gauge). To calibrate each investigated branch we need to determine the constant, $a$.

$a=$ moment $/$ strain

The bridge circuit signal of two-gauge method is amplified when the moment changes, thus increasing the accuracy of measurement.

\subsection{Branch weight monitoring}

The changes of strain $(\varepsilon)$ of branches were monitored continuously during the entire experiment period. To calculate the changes in weight of branches $(\Delta W)$, the constant, $a$, obtained from calibration results for each specific branch was multiplied by the measured strain value $(\Delta \varepsilon)$ and then divided by distance $L$. This relationship can be expressed by the following formula:

$\Delta W=\Delta \varepsilon a / L$

\section{Results and discussion}

\subsection{Diurnal changes in branch weight in Araucaria cunninghamia}

The diurnal changes in branch weight of A. cunninghamia from August 17th to 21st, 1999 are presented in Fig. 2. It is clear that the branch reached maximum weight at 7:00 daily and minimum weight between noon and 16:00. The calibration between strain and bending moment is shown in Fig. 2 $(a=$ moment $/$ stain $=1313 \mathrm{~N} \mathrm{~cm} / 1000 \mu \varepsilon)$. Bending moment $(y)$ changed proportionally to the strain $(x)$, and can be expressed as $y=a x$. The coefficient, $a$, for this specific branch of $A$. cunninghamia was 1.313 . Only light breezes occurred between the 17th 


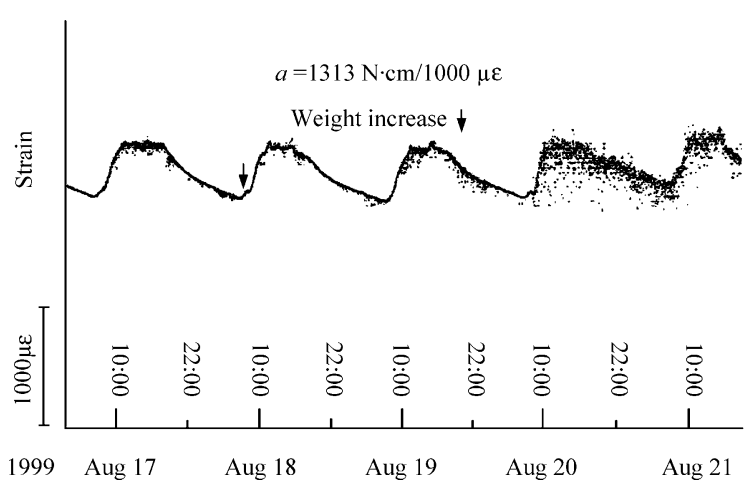

Fig. 2. Record showing diurnal change in branch weight of Araucaria cunninghamii. Calibration constant $a=1313 \mathrm{~N} \mathrm{~cm} / 1000 \mu \varepsilon$.

and 19th, and it was windy between 20th and 21st. Although, there were scattered dots on the record for the last two days, caused by waving branches, the basic profile of curve under the influence of strong wind was still the same as that observed on windless days. This clearly confirms the effectiveness of our non-destructive continuous monitoring technique. The diurnal change in branch weight expressed as mass was about $0.43 \mathrm{~kg}$, which is $3.5 \%$ of branch fresh weight. As an example for calculation, the average diurnal change in branch strain was $419 \mu \varepsilon$, that equaled $550 \mathrm{~N} \mathrm{~cm}$ and the length $L$ measured was $130 \mathrm{~cm}$, so the change in branch weight was:

Because : Moment $=\mathrm{WL}$ or Moment $/ L=W$

Thus : $550 \mathrm{~N} \mathrm{~cm} / 130 \mathrm{~cm}=4.23 \mathrm{~N}$

Since $1 \mathrm{~kg} \mathrm{f}=9.8 \mathrm{~N}$ (Newton), a weight change of $4.23 \mathrm{~N}$ equals a mass change of $0.43 \mathrm{~kg}$. Heavy rain first occurred at 17:00, July 30th, giving the branch a maximal moment change of $2420 \mathrm{~N} \mathrm{~cm}$, equal to a mass change of $1.9 \mathrm{~kg}$ rainfall interception (Fig. 3). The branch showed a rainfall interception of $1.4 \mathrm{~kg}$ as soon as the rain stopped, about 30 min later. Heavy rain occurred again at about 19:00, lasting for about an hour and bringing the maximum rainfall interception for the branch up to $2.2 \mathrm{~kg}$. Then the intercepted rainfall of the branch decreased to $2 / 3$ of the maximum weight as soon as the rain stopped. The strain regained its normal curve by 9:00 of the following morning. The dotted line was predicted from the curve obtained from the day without rain. Heavy rain again occurred at 19:00, August 2nd,

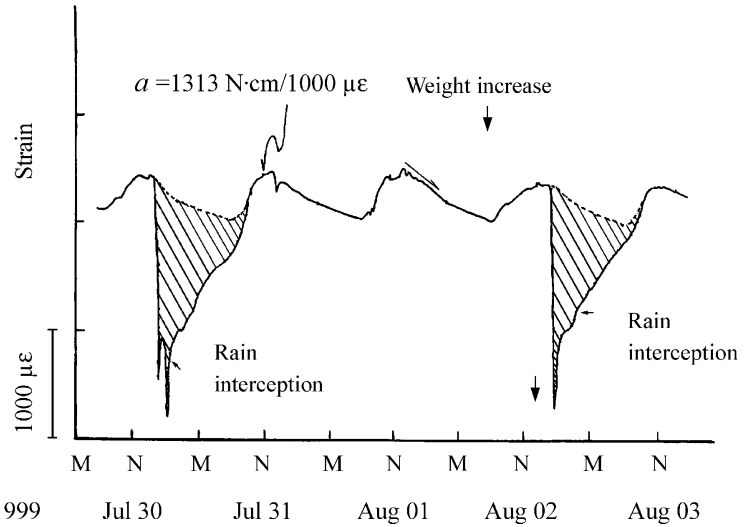

Fig. 3. Diurnal change in weight of branch of Araucaria cunninghamii. $\mathrm{N}$, noon; M, midnight. The precipitation of 36.5 and $17.5 \mathrm{~mm}$ was recorded for July 30th and August 2nd, respectively.

and the intercepted rainfall was about $2.1 \mathrm{~kg}$. The overall precipitation was $36.5 \mathrm{~mm}$ for July 30th and $17.5 \mathrm{~mm}$ for August 2nd. Even though the former was twice the latter, the amount of rainfall interception by the branch was roughly the same. Thus, the maximum interception capacity was estimated to be $2.2 \mathrm{~kg}$ for that specific branch. The effect of rainfall interception can be calculated from the shaded area in Fig. 3. This indicates that the amount of rainfall interception together with the duration can be used as an index for the effect of rainfall interception. In the tested example of A. cunninghamia, there were a total of 24 branches of roughly equal size, so an estimated rainfall interception by the canopy can therefore be obtained $(24 \times 2.2=52.8 \mathrm{~kg})$. Assuming a density of 500 trees per hectare, then the estimated canopy storage capacity will be $2.64 \mathrm{~kg} / \mathrm{m}^{2}$ or $2.64 \mathrm{~mm}$ depth equivalent.

\subsection{Diurnal changes in branch weight in Neolitsea parvigemma}

A different situation occurred in the broad-leaved tree species, $N$. parvegemma (Fig. 4). The days were sunny from September 7th to 12th, 1999 with the exception of showers at 15:00, September 9th (precipitation $0.2 \mathrm{~mm}$ ). As shown in Fig. 4, the calibration values of moment and strain were 172.9, 134.7, 115.1, and $796.3 \mathrm{~N} \mathrm{~cm} / 1000 \mu \varepsilon$ for branches $\mathrm{A}, \mathrm{B}, \mathrm{C}$, and D, respectively. The distances $(L)$ between the center of gravity of branch and strain 


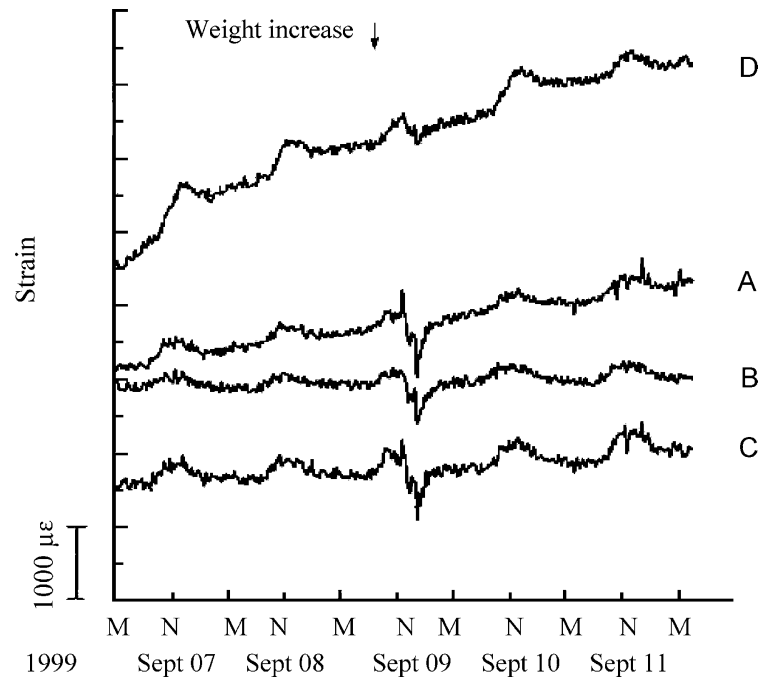

Fig. 4. Diurnal change in weight of branches on sunny days of Neolitsea parvigemma. A, B, C, D, weight change of branches; calibration constant $a$ for A, $172.9 \mathrm{~N} \mathrm{~cm} / 1000 \mu \varepsilon$; B,$\quad 134.7 \mathrm{~N} \mathrm{~cm} / 1000 \mu \varepsilon ; \quad C, \quad 115.1 \mathrm{~N} \mathrm{~cm} / 1000 \mu \varepsilon$ and $\mathrm{D}$, $796.3 \mathrm{~N} \mathrm{~cm} / 1000 \mu \varepsilon$. Estimated horizontal distance from center of gravity of branch to strain gauge $(L)$ for A, $72 \mathrm{~cm} ; \mathrm{B}, 67 \mathrm{~cm}$; C, $61 \mathrm{~cm} ; \mathrm{D}, 100 \mathrm{~cm}$.

gauge were 72, 67, 61, and $100 \mathrm{~cm}$ for branches A, B, $\mathrm{C}$, and $\mathrm{D}$, respectively. The changes of branch weight can be estimated by converting the measured values of strain into moment, which then is divided by distance $(L)$. The daily changes in weight of branches A, B, C, and $\mathrm{D}$, were found to be $65,47,64$, and $270 \mathrm{~g}$, respectively. Presumably, transpiration at daytime and dew deposition during the night caused the weight changes in branches. The strain of branch D increased upwards during the experiment (Fig. 4) indicating a decrease in weight. This could either be caused by a decrease in the water content of branch $\mathrm{D}$, or by an increase of tension wood in the top part of the branch, causing it to curve upwards (Zimmermann and Brown, 1974). Further study is needed to clarify this situation. From August 25th to 30th, thunderstorms occurred in the afternoons from 14:00 to 15:00 (Fig. 5). For example, in the afternoon thunderstorm on August 28th, branch A had maximum rainfall interception estimated to be about $0.44 \mathrm{~kg}$, branch B had $0.30 \mathrm{~kg}$, branch $\mathrm{C}$ had $0.33 \mathrm{~kg}$, and branch D had $0.91 \mathrm{~kg}$.

Our results are comparable with the discovery from the direct measurement of water storage in Sitka

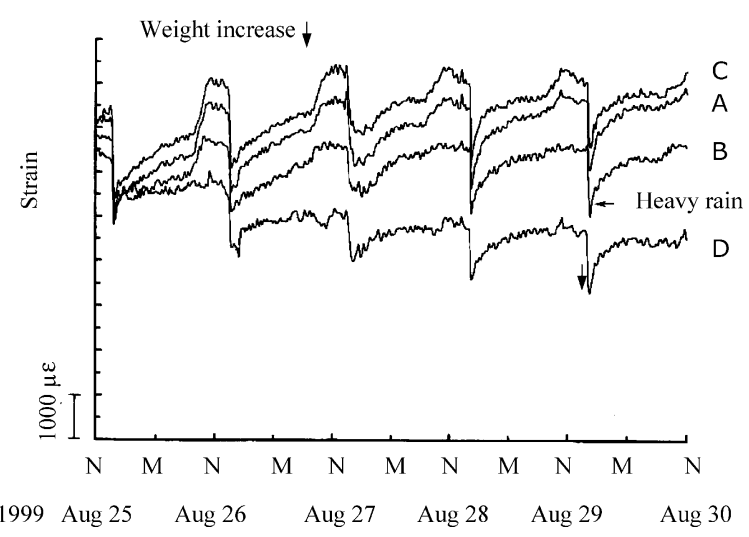

Fig. 5. Diurnal change and rainfall intercepted by branches of Neolitsea parvigemma on days of heavy rain. Legend A, B, C and D please see the legend in Fig. 4. The precipitation of 62, 23, 7, 10.4, 17.6 and $2.3 \mathrm{~mm}$ was recorded for August 25th, 26th, 27th, 28th, 29 th and 30th, respectively.

spruce (Picea sitchensis) by Hancock and Crowther (1979), who used displacement transducers attached to branches. The branches chosen ranged from 1.5 to $2.0 \mathrm{~m}$ in length, from 1.6 to $2.6 \mathrm{~cm}$ in diameter, and had average water storage capacities $0.27 \mathrm{~kg}$ per branch. In fact, they were also quite successful in using the wire strain gauge method, but for reasons of cost and practical inconvenience this method was abandoned in the late 1970s. The cost and practicality of instrumentation at present time has changed a lot since then, and the strain gauge method deserves attention.

Weight change in the branch exhibited the same trend as strain in the branch. By comparing Figs. 4 with 5 , the daily changes in branch weight and strain were more dramatic in August than in September, a phenomenon probably related to the differences in weather. Substantial precipitation of $62,23,7,10.4$, 17.6, and $2.3 \mathrm{~mm}$, was recorded from August 25th to 30 th, respectively, providing enough water to the soil to cause large diurnal changes in strain. On the other hand, the weather was mostly sunny between September 7 th and 12 th, reducing the water content in the soil, and causing smaller diurnal changes in strain. This inference is supported by the findings of Huang and Chen (1999) who studied water retention of a Cinnamomum kanehirae sapling. Their results showed that the changes in strain of the stem diameter were responsive to the changes in soil water content. 


\subsection{Advantage in using strain gauge method to measure the rainfall interception by tree}

In comparing the strain gauge method with the displacement transducer method reported by Hancock and Crowther (1979), we should understand the pros and cons of material mechanics. From the theory of bending cantilever with concentrated load at the free end (Timoshenko, 1955), the bending moment at any point of the cantilever linearly increases with the decrease of its distance from the fixed end. The same also occurs to bending stress and strain. On the other hand, the vertical displacement of cantilever decreases rapidly with the decrease of distance from fixed end. Clearly, in order to increase the measurement sensitivity, the strain gauge should be placed as close to the fixed end as possible, whereas the displacement transducer should be installed as far from the fixed end as possible. However, it is inconvenient to install the transducer on the trunk, and any minor looseness of the device during the experiment will cause significant measurement error. Therefore, in our opinion the strain gauge technique is more convenient than the displacement transducer method.

As the method presented in this article, diurnally changes in the water content of branches or the rainfall interception by branches can be measured by the strain gauge method. The major source of error in this method is error in the weight center of branch that was determined visually. The error for visual determination was $6 \%$ according to Hancock and Crowther (1979). The more accurate way to measure is to cut the branch after the experiment to obtain the weight center of a branch. The strain gauge method can be also applied to the measurement of diurnally diameter changes of trunk. Since the diameter changes are directly related to the changes of water potential, the water status of tree or sapling can thus be monitored. Another potential application of the strain gauge method in forestry is for connection to automatic irrigation systems in nursery management.

\section{Conclusion}

A tree can be considered as an elastic body, and the diurnal change in water loading of tree can be continuously monitored by using the strain gauge method. Strain gauges are attached to the inner bark parallel to the main axis of stem. It is used to measure the moment change resulting from the diurnal fluctuation in water content in branch. The increase in branch weight due to rainfall interception is followed by change in moment. After appropriate calibration, change in moment can be converted to change in weight, so the capacity of rainfall interception and the day/night change in water content of branch can be estimated.

\section{References}

Alavi, G., Jansson, P.E., Hallgren, J.E., Bergholm, J., 2001. Interception of a dense spruce forest, performance of a simplified canopy water balance model. Nordic Hydrology 32, 265-284.

Amatya, D.M., Skaggs, R.W., 2001. Hydrologic modeling of a drained pine plantation on poorly drained soils. Forest Science 47, 103-114.

Calder, I.R., 2001. Canopy processes: implications for transpiration, interception and splash induced erosion, ultimately for forest management and water resources. Plant Ecology 153, 203-214.

Chappell, N.A., Bidin, K., Tych, W., 2001. Modelling rainfall and canopy controls on net-precipitation beneath selectively-logged tropical forest. Plant Ecology 153, 215-229.

Davie, T.J.A., Durocher, M.G., 1997. A model to consider the spatial variability of rainfall partitioning within deciduous canopy. I. Model description. Hydrological Processes 11, 1509-1523.

Dolman, A.J., 1987. Summer and winter rainfall interception in an oak forest. Predictions with an analytical and a numerical simulation model. Journal of Hydrology 90, 1-9.

Dunin, F.X., O’Loughlin, E.M., Reyenga, W., 1988. Interception loss from eucalypt forest: Lysimeter determination of hourly rates for long term evaluation. Hydrological Processes 2, 315-329.

Gash, J.H.C., Morton, A.J., 1978. An application of the Rutter model to the estimation of the interception loss from Thetford Forest. Journal of Hydrology 38, 49-58.

Hancock, N.H., Crowther, J.M., 1979. A technique for the direct measurement of water storage on a forest canopy. Journal of Hydrology 41, 105-122.

Huang, Y.S., Chen, S.S., 1999. Continuous monitoring of stem diameter fluctuations of stout camphor saplings under different environmental conditions. Taiwan Journal of Forest Science 14, 307-314.

Jame, W.D., William, F.R., 1978. Experimental Stress Analysis, second ed. McGraw-Hill, New York pp. 153-154.

Johnson, R.C., 1990. The interception, throughfall and stemflow in a forest in highland Scotland and the comparison with other upland forests in the U.K.. Journal of Hydrology 118, 281-287.

Kikata, Y., 1972. The effect of lean on growth stress in Pinus densiflora. Mokuzai Gakkaishi 18, 443-449. 
Rutter, A.J., Morton, A.J., 1977. A predictive model of rainfall interception in forests, III. Sensitivity of the model to stand parameters and meteorological variables. Journal of Applied Ecology 14, 567-588.

Rutter, A.J., Kershaw, K.A., Robins, P.C., Morton, A.J., 1971. A predictive model of rainfall interception in forest, I. Derivation of the model from observations in a plantation of Corsican pine. Agricultural Meteorology 9, 367-384.

Rutter, A.J., Morton, A.J., Robins, P.C., 1975. A predictive model of rainfall interception in forest, II. Generalisation of the model and comparison with observations in some coniferous and hardwood stands. Journal of Applied Ecology 12, 367-380.
Timoshenko, S., 1955. Strength of Materials, third ed. D. Van Nostrand Co., Inc, New York pp.149-152.

Xiao, Q.F., McPherson, E.G., Ustin, S.L., Grismer, M.E., 2000. A new approach to modeling tree rainfall interception. Journal Geophysical Research-Atmospheres 105, 29173-29188.

Yoshida, M., Yamamoto, O., Tamai, Y., Sano, Y., Terazawa, M., Okuyama, T., 1999. Investigation of change in tangential strain on the inner bark of the stem and root of Betula platyphylla var. japonica and Acer mono during sap season. Journal of Wood Science 45, 361-367.

Zimmermann, M.H., Brown, C.L., 1974. Trees Structure and Function. Springer, New York pp. 98-105. 